\title{
Measurements and Acoustic Analyses of Infrasound Noise Emitted by Operation of Small, Building Mounted Wind Farm
}

\author{
R. PierzGA*, T. Boczar And D. Wotzka \\ Faculty of Electrical Engineering, Automatic Control and Computer Science, Opole University of Technology, \\ Prószkowska 76, 45-758 Opole, Poland
}

(Received July 8, 2014; in final form April 17, 2015)

\begin{abstract}
Operation of modern wind turbines generates infrasound noise which is known as potentially harmful for humans. In presented study, measurements of infrasound noise generated by operation of five vertical axis, building mounted, small wind turbines were conducted. Measurements were taken in urban area at several points and different distances from the installation. Analyses were performed to determine the level of emitted infrasound noise in vicinity of the installation. Comparative analyses were carried out and the achieved results were referred to the limits of sound pressure intensity level of infrasound signals as specified for the working environment in accordance with the Polish standard PN-Z-01338.
\end{abstract}

DOI: 10.12693 /APhysPolA.128.294

PACS: 43.28.Dm, 88.50.gp, 88.50.jj

\section{Introduction}

Operating wind turbine generates audible and inaudible noise called infrasound [1-4] and vibrations [5-8]. Small wind turbines can also be a source of infrasound noise which is defined as the acoustic emission at the frequency range from $2 \mathrm{~Hz}$ to $20 \mathrm{~Hz}$ [9]. Recent studies of infrasound indicate that sound pressure levels of infrasound noise generated by horizontal axis wind turbine (HAWT) has a linear level of $80-90 \mathrm{~dB}$ which is unlikely harmful $[10,11]$, but it is known that exposure to infrasound noise may result with problems with concentration, malaise, increased sleepiness, reduction in of labor productivity, balance disorders, impaired psychomotor skills or even syndrome called in literature as vibroacoustic disease are being related with exposure to high levels of infrasound noise $[1-3,12,13]$. Those problems may be even greater in relation to small wind turbines. Small wind turbines can be installed on residential or public buildings $[14,15]$ where the infrasound noise generated by operation of small wind turbines can be higher because of high levels of wind turbulence [16]. Therefore it is important to perform evaluation of infrasound noise emission generated by small wind turbines installed in highly populated area. This is even more important because of the lack of legal norms regulating the level of infrasound noise generated by the small wind turbines. As a commentary, it is important to point out that infrasound noise generated by operation of wind turbines is caused by phenomena of turbulence, turbulences of air particles caused by "sharp" edges of the turbine, for example: blades, generator.

\section{Test object}

This study presents results of measurement of infrasound noise emission generated by small wind farm containing five small, vertical axis, wind turbines (Fig. 1).

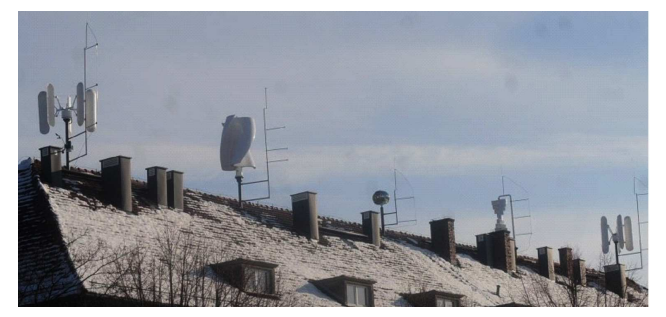

Fig. 1. Test subject, small wind farm containing five small, vertical axis, wind turbines.

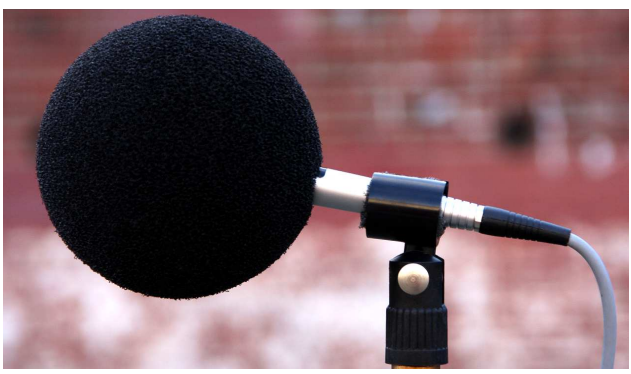

Fig. 2. Windscreen used during measurements, type UA-0234.

Each turbine nominal power is $1 \mathrm{~kW}$. All five wind turbines are mounted on the same building situated at Opole University of Technology Second Campus. The measurement were taken by the Brüel\&Kjær measurement set containing microphone type 4190L1 placed on a tripod. During measurements microphone were equipped with spherical windscreen type UA-0234 shown in Fig. 2. The LAN-XI type 3050 infrasound meter and computer with dedicated software PulseLabShop v. 15.1. Calibration of the microphone was conducted using acoustic calibrator KA-50 I class calibrator. There were no differences in sound pressure levels before and after the measurement. The measurements of weather conditions 
were performed using the weather station Ventage Pro 2, type $6152 \mathrm{EU}$. Weather conditions were performed at the top of the roof where the wind turbines were mounted. The weather conditions at the time of measurement were presented in Table I. Measurements were taken in five points at different places of Second Campus and distances form wind farm. P1 - $90 \mathrm{~m}, \mathrm{P} 2-94 \mathrm{~m}, \mathrm{P} 3-190 \mathrm{~m}$, $\mathrm{P} 4-250 \mathrm{~m}, \mathrm{P} 5-250 \mathrm{~m}$ in a straight line (Fig. 3). Point 1 was located at roof platform of a nearby building $\left(N=50^{\circ} 39^{\prime} 8.7^{\prime \prime} ; E=17^{\circ} 54^{\prime} 18.6^{\prime \prime}\right)$. Point 2 was located at the same building roof platform as point 1 at the opposite side of the roof the roof $\left(N=50^{\circ} 39^{\prime} 8.5^{\prime}\right.$; $\left.E=17^{\circ} 54^{\prime} 18.2^{\prime \prime}\right)$. Point 3 was located at the acoustic background of a Foreign Language Center building $\left(N=50^{\circ} 39^{\prime} 8.7^{\prime \prime} ; E=17^{\circ} 54^{\prime} 11.1^{\prime \prime}\right)$. Point 4 was located at acoustic background between Faculty of Physical Education and Physiotherapy and garages buildings $\left(N=50^{\circ} 39^{\prime} 12.1^{\prime \prime} ; E=17^{\circ} 54^{\prime} 7.5^{\prime \prime}\right)$. Point 5 was located in acoustic background between garages buildings $\left(N=50^{\circ} 39^{\prime} 14.4^{\prime \prime} ; E=17^{\circ} 54^{\prime} 8.3^{\prime \prime}\right)$. Research has been extended on April 2015 to 7 measurement points. Both additional points were situated in the building where wind turbines were mounted. Point 6 were situated at classroom on first floor. Point 7 were situated in classroom on second floor. Measurements were performed on tripod, $1.5 \mathrm{~m}$ above ground according to PN-Z-01338:2010 [17]. At least three 1 min samples for every measured wind speed were taken. Measurements in P6 and P7 were taken at night hours to minimize influence of unknown infrasound noise sources. Main goal was to determine the impact of infrasound noise generated by operation of specified wind farm.

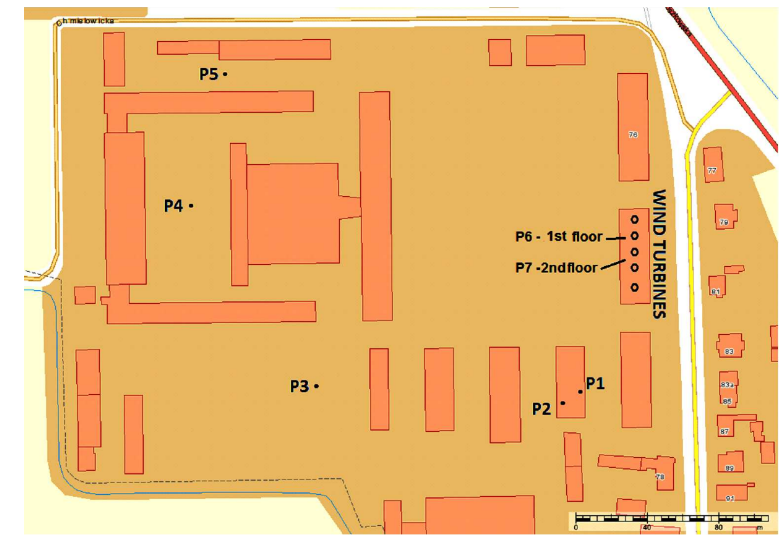

Fig. 3. Placement of measurement points [18].

TABLE I

Weather conditions at the time of measurement, 6 Dec 2013; 7 Dec 2013; 1-2 Apr 2015.

\begin{tabular}{c|c|c|c|c|c|c|c|c|c|c|c|c}
\hline \hline & \multicolumn{3}{|c|}{ Max } & \multicolumn{3}{c|}{ Min } & \multicolumn{3}{c|}{ Mean } & \multicolumn{3}{c}{$\begin{array}{c}\text { Standard } \\
\text { deviation [\%] }\end{array}$} \\
\hline $\begin{array}{c}\text { wind } \\
\text { speed [m/s] } \\
\text { wind }\end{array}$ & 15.6 & 13 & 11.2 & 4.5 & 6.7 & 2.2 & 8.8 & 9.7 & 5.1 & 19.3 & 13.7 & 35.5 \\
gust [m/s] & 20.6 & 17 & 15.2 & 6.7 & 9.4 & 3.1 & 12.7 & 12.9 & 7.2 & 18.7 & 13.5 & 34.8 \\
temp [ $\left.{ }^{\circ} \mathrm{C}\right]$ & 3.7 & 1.2 & 5.1 & 1.9 & 0.6 & 1.1 & 2.6 & 1.0 & 4.0 & 19.8 & 23.2 & 28.9 \\
humidity [\%] & 77 & 73 & 91 & 60 & 67 & 63 & 69.7 & 70.1 & 73.9 & 7.5 & 3 & 10.2 \\
dewpoint [ $\left.{ }^{\circ} \mathrm{C}\right]$ & -1.7 & -3.5 & 0.4 & -3.4 & -4.3 & -1.8 & -2.4 & -3.9 & -0.7 & 22.1 & 5.7 & 77.3 \\
rainfall & 0 & 0 & 0 & 0 & 0 & 0 & 0 & 0 & 0 & & -
\end{tabular}

\section{Evaluating the impact of infrasound noise emission of tested subject}

To evaluate the infrasound noise generated by tested small wind farm, wave forms of frequency spectra for different wind speeds were computed for each of five measuring points and it was expressed in decibels relative to threshold of audibility, which is $p_{0}=20 \mu \mathrm{Pa}$. The analyzed frequency range was extended to low frequency noise and was from $2 \mathrm{~Hz}$ to $100 \mathrm{~Hz}$. Sound pressure level of infrasound noise for a given wind speed and frequency range was determined as arithmetic mean from all recorded sound pressure levels for the speed. Thus obtained results were presented in graphs (Figs. 4-9).
Based on the characteristics in Figs. 4-9 it can be concluded that the highest sound pressure level is at frequency $1-2 \mathrm{~Hz}$ and it was in range from 90 to $108 \mathrm{~dB}$. Sound pressure level was higher for higher wind speed. Also it can be stated that the highest measured sound pressure levels was at measuring point no. 3 and the lowest sound pressure level was at measuring point no. 4 . In all five measuring points the sound pressure level is decreasing with frequency increase from about 90-108 dB at $2 \mathrm{~Hz}$ to about $55-65 \mathrm{~dB}$ at $20 \mathrm{~Hz}$ and to about $37-$ $52 \mathrm{~dB}$ at $100 \mathrm{~Hz}$. It can be also stated that for all measuring points the recorded sound pressure level was lower than thresholds of audibility for specified frequencies. 


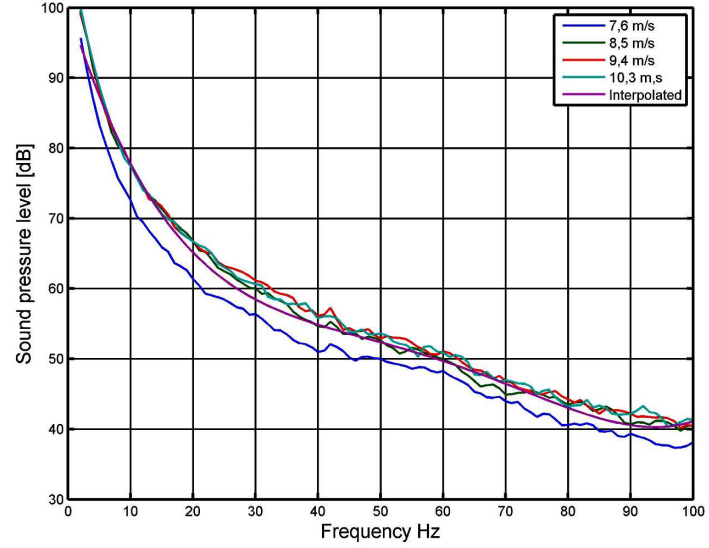

Fig. 4. Sound pressure level in measuring point 1 at different wind speeds.

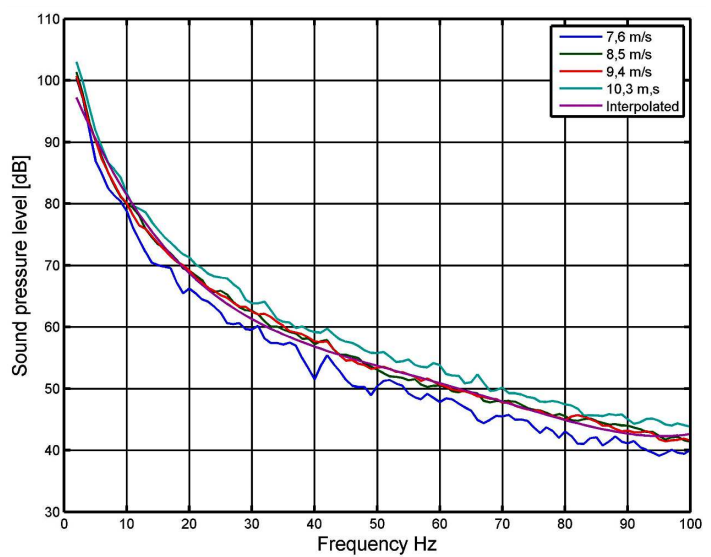

Fig. 5. As in Fig. 4, but for point 2.

The infrasound threshold audibility reference values from literature were presented in Table II.

Analyzing characteristics shown in Figs. 4-8 there can also be stated that no resonant frequency can be found at these characteristics. At measuring point 4 (Fig. 7) there are two frequency bands with higher sound pressure levels from 29 to $35 \mathrm{~Hz}$ and from 61 to $69 \mathrm{~Hz}$. This occurs only

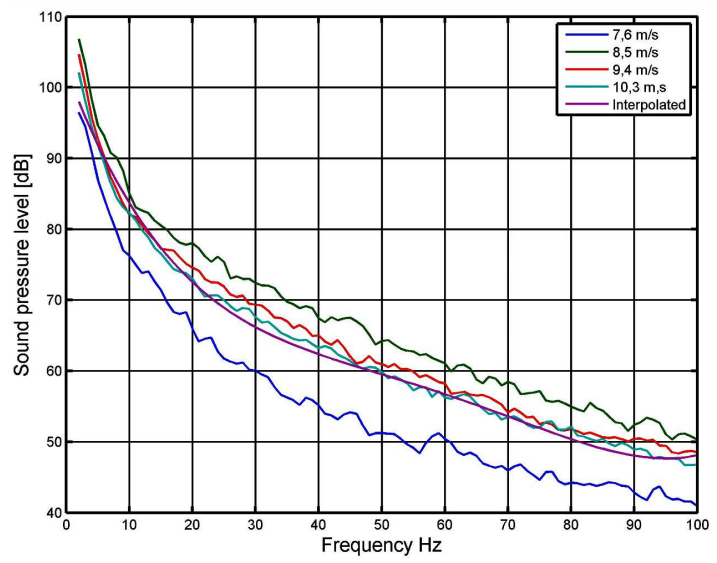

Fig. 6. As in Fig. 4, but for point 3.

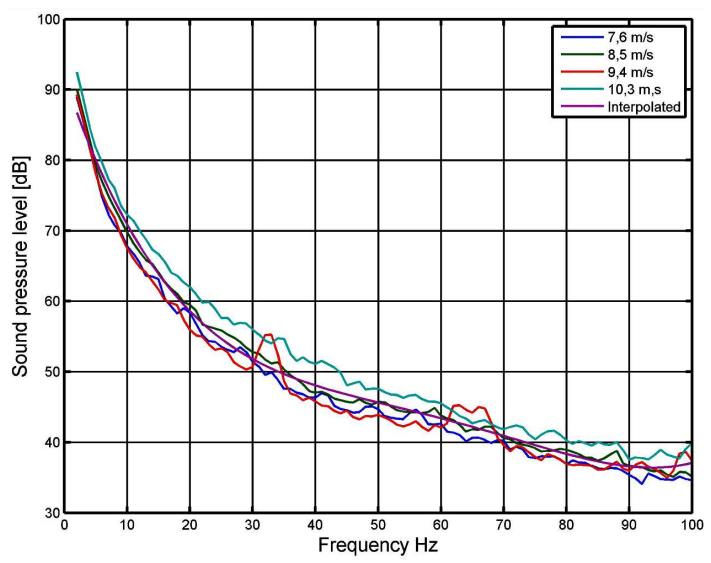

Fig. 7. As in Fig. 4, but for point 4.

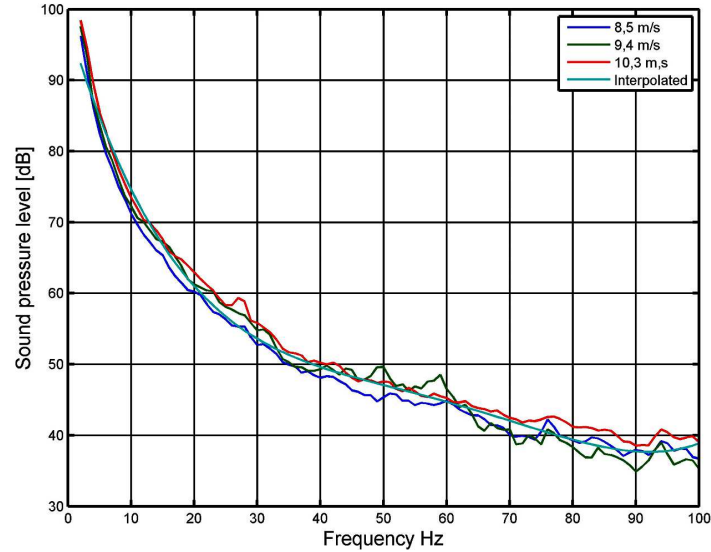

Fig. 8. As in Fig. 4, but for point 5.

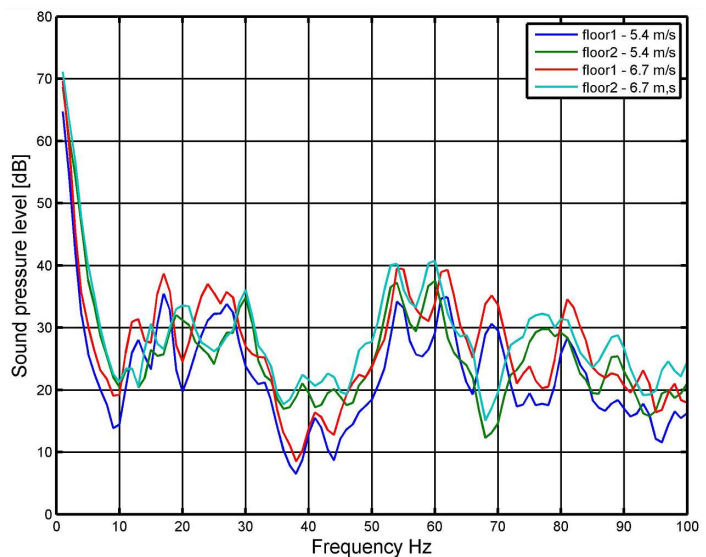

Fig. 9. As in Fig. 4, but for points 6 (floor1) and 7 (floor2).

TABLE II

Infrasound audibility threshold levels [13].

\begin{tabular}{c|c|c|c|c|c|c|c|c|c|c|c|c|c}
\hline \hline freq $[\mathrm{Hz}]$ & 4 & 8 & 10 & 12.5 & 16 & 20 & 25 & 31.5 & 40 & 50 & 63 & 80 & 100 \\
\hline level $[\mathrm{dB}]$ & 107 & 100 & 97 & 92 & 88 & 79 & 69 & 60 & 51 & 44 & 38 & 32 & 27
\end{tabular} 
for wind speed $9.4 \mathrm{~m} / \mathrm{s}$ so it is probably with influence of unknown source of infrasound noise. Analyzing characteristics shown in Fig. 9 which represents infrasound noise spectra inside building, large irregularities can be observed. At points 6 and 7 located on the first and second floor there is an increase of sound pressure level at frequencies: at $10 \mathrm{~Hz}$ to $20 \mathrm{~Hz}$. There is also an increase of sound pressure level at frequencies about $53 \mathrm{~Hz}$ and $60 \mathrm{~Hz}$ which indicates resonant frequencies. It can be also stated that infrasound noise SPL measured at points 6 and 7 , which were inside the building, were much lower than outside the building and was about $65-70 \mathrm{~dB}$ at $1 \mathrm{~Hz}$ and about 20 to $33 \mathrm{~dB}$ at $20 \mathrm{~Hz}$.
Next stage was to compute interpolation function for shown characteristics in Figs. 4 to 8. Fourth-degree polynomial was chosen and computed for average sound pressure level for every measuring point. The results have been shown in Figs. 4-7 as "interpolated". Interpolation was made as average of every wind speed recorded in measuring point.

In the final stage of the analysis comparison of the values of sound pressure level corrected with the G-weighting frequency characteristic to a limit values defined in relevant standards for workplaces was performed. The methodology of comparison is described in [15]. Results of comparison were presented in Table III.

TABLE III

Comparative tabulation of equivalent sound pressure level values referred to 8-hour working day or a working week ( $8 \mathrm{~h}$ ESP) derived from measurements and current regulations for measuring points.

\begin{tabular}{|c|c|c|c|}
\hline \multirow{2}{*}{$\begin{array}{l}\text { One-third octave } \\
\text { band center } \\
\text { frequency }[\mathrm{Hz}]\end{array}$} & \multicolumn{3}{|c|}{$8 \mathrm{~h}$ ESP determined from measurements } \\
\hline & $\begin{array}{c}\text { for point } 1 \\
{[\mathrm{~dB}]}\end{array}$ & $\begin{array}{c}\text { for point } 2 \\
{[\mathrm{~dB}]}\end{array}$ & $\begin{array}{c}\text { for point } 3 \\
{[\mathrm{~dB}]}\end{array}$ \\
\hline $10,12.5,16$ & $76.36,74.97,75.02$ & $80.13,78.80,78.42$ & $81.41,81.42,81.54$ \\
\hline 20 & 75.38 & 78.94 & 82.89 \\
\hline 25 & 65.77 & 69.32 & 73.73 \\
\hline $31.5,40$ & $54.93,40.35$ & $57.86,42.37$ & $62.96,48.69$ \\
\hline \multicolumn{2}{|c|}{$8 \mathrm{~h} \mathrm{ESP}$ determined from measurements } & \multirow{2}{*}{$\begin{array}{c}8 \text { h ESP based } \\
\text { on [17] reference } \\
\text { ESP [dB] }\end{array}$} & \multirow{2}{*}{$\begin{array}{l}8 \text { h ESP workplaces } \\
\text { requiring high } \\
\text { attention }[17][\mathrm{dB}]\end{array}$} \\
\hline $\begin{array}{c}\text { for point } 4 \\
{[\mathrm{~dB}]}\end{array}$ & $\begin{array}{c}\text { for point } 5 \\
{[\mathrm{~dB}]}\end{array}$ & & \\
\hline $72.33,71.56,71.39$ & $69.36,68.70,68.21$ & \multirow{4}{*}{102} & \multirow{4}{*}{86} \\
\hline 71.49 & 68.96 & & \\
\hline 61.57 & 59.08 & & \\
\hline $50.17,35.20$ & $49.02,33.57$ & & \\
\hline \multicolumn{2}{|c|}{$8 \mathrm{~h}$ ESP determined from measurements } & \multirow{2}{*}{$\begin{array}{c}8 \mathrm{~h} \text { ESP based } \\
\text { on [17] reference } \\
\text { ESP [dB] }\end{array}$} & \multirow{2}{*}{$\begin{array}{l}8 \text { h ESP workplaces } \\
\text { requiring high } \\
\text { attention }[17][\mathrm{dB}]\end{array}$} \\
\hline $\begin{array}{c}\text { for point } 6 \\
{[\mathrm{~dB}]}\end{array}$ & $\begin{array}{c}\text { for point } 7 \\
{[\mathrm{~dB}]}\end{array}$ & & \\
\hline $\begin{array}{c}16.82,31.58,38.83 \\
32.07 \\
37.86 \\
22.06,-0.65\end{array}$ & $\begin{array}{c}20.84,24.43,32.45 \\
42.37 \\
29.15 \\
30.82,6.55\end{array}$ & 102 & 86 \\
\hline
\end{tabular}

\section{Conclusions}

Based on the research studies, analysis and comparisons, the following conclusions can be stated:

- The sound pressure level of infrasound noise generated by tested small wind farm increases with wind speed.

- The sound pressure level of infrasound noise generated by tested small wind farm was below the threshold of audibility.

- The sound pressure level of infrasound noise measured inside building was much lower than measured outside the building and much lower than referenced.

- The sound pressure level of infrasound noise was comparable at both measuring points located in building.

- The highest sound pressure level of infrasound noise was measured in measuring point 3 and the lowest in measuring point 4 both located in acoustic background.

- In the case of measuring point 3 the measured values exceeded slightly the values stated in relevant standards. 
The Authors believe that there exists a necessity for further research works in this area, which will include a wide range of micro-wind turbines of different construction. This applies to measurements of sound pressure level of generated low-frequency signals, as well as to determination of the effect of a number of parameters on the results obtained. It is also planned to model the physical processes associated with the phenomenon of generation and propagation of infrasound signals. Currently in this area some research works are carried out within the dissertation of one of the Authors.

\section{References}

[1] L. Knopper, Ch. Ollson, Environmental Health 10, 78 (2011).

[2] J. Jakobsen, J. Low Freq. Noise Vibrat. Active Control 24, 76 (2005).

[3] H. Møller, Ch. Pedersen, J. Acoust. Soc. Am. 129, 6 (2011).

[4] Sung Soo Jung, Wan-Sup Cheung, J. Korean Phys. Soc. 53, 1897 (2008).

[5] M. Szmechta, Acta Phys. Pol. A 124, 574 (2013).
[6] T. Malec, T. Boczar, D. Wotzka, Pomiary Automatyka Kontrola 9, 773 (2012).

[7] D. Wotzka, T. Boczar, T. Malec, R. Pierzga, Acta Phys. Pol. A 124, 595 (2013).

[8] T. Boczar, T. Malec, D. Wotzka, Acta Phys. Pol. A 122, 850 (2012).

[9] PN-ISO 7196:2002, Acoustics - Frequency-weighting characteristic for infrasound measurements.

[10] A. Zagubień, R. Ingielewicz, Pomiary Automatyka Kontrola 59, 725 (2013) (in Polish).

[11] M. Wojsznis, Vibrat. Phys. Syst. 26, 327 (2014).

[12] A. Salt, T. Hullar, Hearing Res. 268, 1 (2010).

[13] G. Leventhall, Prog. Biophys. Mol. Biol. 93, 130 (2007).

[14] J. Taylor, C. Eastwick, C. Lawrence, R. Wilson, Renewable En. 55, 120 (2013).

[15] R. Pierzga, T. Boczar, D. Wotzka, D. Zmarzły, Acta Phys. Pol. A 124, 542 (2013).

[16] T. Rogers, S. Omer, Renewable En. 41, 180 (2011).

[17] PN-Z-01338:2010, Acoustic - Measurement and assessment of infrasound noise at work (in Polish).

[18] http://mapy.opolskie.pl/ April 2014 (in Polish). 